\title{
PENGARUH MARKETING MIX DAN SIKAP KONSUMEN TERHADAP KEPUTUSAN MENGIKUTI KURSUS DI LPK PROGRESS PARE
}

\author{
Oleh : \\ M. DIAN RUHAMAK,SE.,MM \\ Dosen Fakultas Ekonomi Universitas Kadiri \\ dianru@unik-kediri.ac.id
}

\begin{abstract}
The purpose of this study was to analyze the factors that influence consumer decisions through the marketing mix and consumer attitudes toward decisions follow a course in progress pare LPK, to see the extent to which decisions are taken through the marketing mix and the attitude towards the decision to follow a course in progress pare LPK. Descriptive analysis showed that the marketing mix variables (price, place, product, promotion, people, physical environment and processes) and consumer attitudes positive influence on the decision to follow the course. Based on the research results, the hypothesis 1 which states, thought to have a positive pegaruh between factors (price, place, product, promotion, people, physical environment and processes) and consumer attitudes positive influence on the decision to follow a course in progress pare LPK.
\end{abstract}

Keyword: Marketing Mix, Constumer Attitudes, Decision

\section{PENDAHULUAN}

Globalisasi yang melanda dunia akhir-akhir ini sangat berpengaruh pada dunia bisnis. Berbagai informasi mengenai kegiatan bisnis semakin mudah diperoleh. Informasi mengenai berbagai jenis produk (barang dan jasa), kualitas produk, distribusi dan pasar, harga, inovasi atau perubahan bentuk akan mengakibatkan perubahan penilaian dan minat masyarakat terhadap produk yang ada. Dunia pendidikan sebagai wujud dan simbol masyarakat modern sangat diperlukan manusia dalam tumbuh dan kembangnya. Saat ini dunia pendidikan bukan hanya sebagai dunia sosial yang non profit yang tidak mencari keuntungan semata, tetapi telah berkembang bentuk dan tempat-tempat pendidikan yang representatif yang juga bergerak di bidang bisnis dalam rangka penyiapan tenaga kerja menjadi satu bisnis yang baru yang sedang dikembangkan pemerintah dengan dikeluarkannya Undang-undang Sisdiknas dimana profesi guru adalah profesional yang sama dengan profesi dokter, advokat dan sebagainya. Demikian juga lembaga pendidikan yang harus berbadan hukum, hal ini berarti tidak jauh berbeda dengan badan hukum bisnis yang lain seperti UD, CV dan PT yang bergerak mencari keuntungan. Menurut Undang-undang Sisdiknas tahun 2003 pendidikan bahwa pendidikan dibagi menjadi dua bagian yaitu pendidikan formal yang berdasarkan tempat, waktu dan kegiatannya dilakukan secara teratur yang meliputi Pendidikan Dasar SD dan SMP dan pendidikan lanjutan SMA - SMK dan Perguruan Tinggi, sedangkan pendidikan non formal - informal adalah yang tempat, waktu dan kegiatannya berdasarkan kesepakatan pendidik, penyelenggara dan warga belajarnya.meliputi Pendidikan Anak Usia Dini (PAUD) usia 2 - 4 tahun, Pendidikan Taman Kanak-kanak (TK) usia 4 - 6 tahun, Pendidikan Keaksaraan Fungsional (KF) bagi buta huruf dan putus sekolah SD 
kelas $2-3$, kemudian Pendidikan Paket A setara SD, Paket B setara SMP dan Paket $C$ setara SMA. Disamping itu ada pendidikan Kursus, dimana kursus ini adalah pendidikan ketrampilan khusus terutama guna mendapatkan ketrampilan life skill sebagai bekal mendapatkan pekerjaan (UU Sisdiknas 2003).

Peserta Kursus adalah generasi muda lulusan SMP / SMA yang berkehendak mencari pekerjaan dengan vokasi yang sesuai bakat dan minat peserta didik. Calon peserta didik kursus memilih pendidikan kursus agar mempunyai bekal ketrampilan dan vokasi yang memadai untuk memasuki dunia kerja. Jenis bidang pendidikan kursus mendukung semua aspek kehidupan mulai dari kursus menjahit, Tata Rias, Tata Kecantikan Kulit, Tata Kecantikan Rambut, Spa, Bahasa Inggris, Komputer, Kursus Satpan dan sebagainya. Lama pendidikan kursus bervariasi dan dapat menyesuaikan sesuai penggunanya, dengan model privat atau rombongan karena sistem pendidikan di kursus itu sendiri menggunakan sistem Andragogi, yaitu pendidikan untuk orang dewasa yang mengarah langsung pada skill yang diperlukan oleh user.

Bisnis di bidang pendidikan tidak lepas dari pengaruh-pengaruh terjadinya perkembangan hebat yang melanda dunia. Peserta didik dihadapkan kepada banyak pilihan kursus mengenai jenis vokasi ketrampilan apa yang ingin didapatkannya.

Kemudahan mendapatkan informasi mengenai perkembangan pendidikan yang mudah diakses melalui media massa, media elektronika, periklanan dan melalui internet, jelas akan berpengaruh pada perubahan minat perilaku konsumen, hal tersebut harus menjadi masukan bagi perusahaan jasa untuk selalu mengikuti perkembangan yang terjadi agar selalu bisa mengusahakan kinerja sesuai dengan minat peserta didik sekaligus menjaga agar tidak terjadi berpindahnya peserta didik dari lembaga kursus ke lembaga kursus yang lain.

\section{Rumusan Masalah}

Perumusan masalah yang diteliti adalah:

1. Apakah ada pengaruh bauran pemasaran dan sikap konsumen secara parsial dan simultan terhadap keputusan mengikuti jasa kursus di LPK Progress Pare ?

2. Manakah dari variabel bauran pemasaran dan sikap konsumen yang berpengaruh dominan terhadap keputusan mengikuti jasa kursus di LPK Progress Pare?

\section{Tujuan Penelitian}

a. Mengetahui dan menjelaskan pengaruh bauran pemasaran dan sikap konsumen terhadap keputusan mengikuti jasa kursus di LPK Progres Pare

b. Mengidentifikasi variabel bauran pemasaran dan sikap konsumen yang berpengaruh dominan terhadap keputusan mengikuti jasa kursus di LPK Progres Pare

\section{Batasan Masalah}

Karena di kota Pare banyak sekali terdapat lembaga kursus maka peneliti memberi batasan penelitian hanya pada lembaga kursus DEC saja karena pertimbangan kemudahan akses lokasi dan DEC salah satu lembaga yang telah cukup lama berdiri di kota pare. 


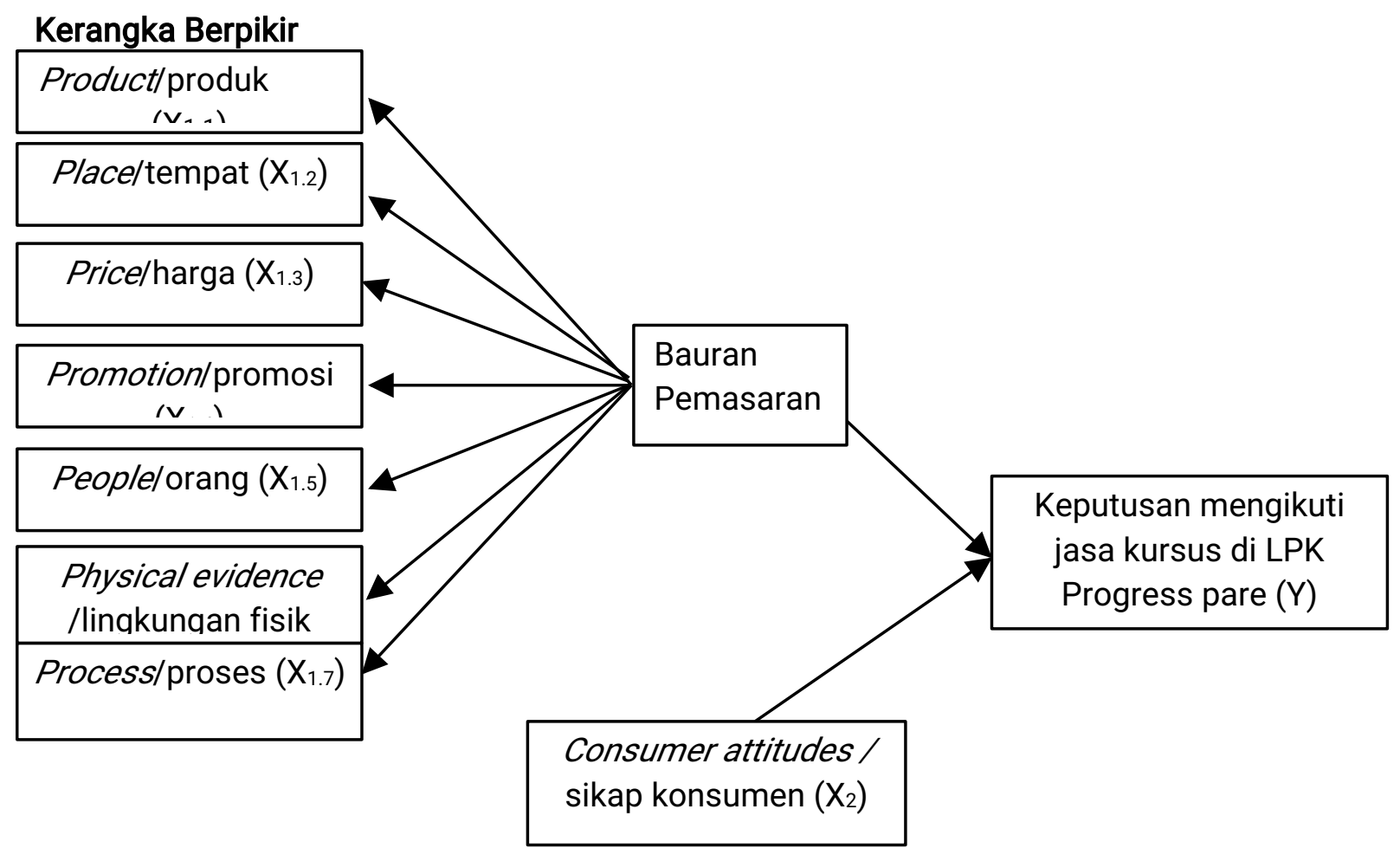

Sumber : Kotler dan Amstrong(2001:337), Setiadi (2003:76), Setiadi (2008:416)

\section{Hipotesis}

Berdasarkan rumusan masalah dan tinjauan pustaka maka pada penelitian ini rumusan hipotesisnya adalah sebagai berikut :

$\mathrm{H}_{1}$ : Terdapat pengaruh bauran pemasaran dan sikap konsumen terhadap keputusan mengikuti jasa kursus.

$\mathrm{H}_{2}$ : Variabel proses berpengaruh dominan terhadap keputusan mengikuti jasa kursus.

\section{Metode Penelitian}

Jenis Penelitian

Sesuai dengan tujuan penelitian yang ingin dicapai dalam penelitian ini yaitu menjelaskan pengaruh antara tiga variabel yang sudah ditetapkan, maka rancangan penelitian yang digunakan adalah penelitian eksplanasi (exsplanatory research). Jenis penelitian ini ditujukan untuk menjelaskan hubungan antar variabel melalui pengujian hipotesis secara statistik. Jenis penelitian ini termasuk 
jenis eksplanatoris (Sugiyono, 2013).

\section{Populasi dan Sampel}

Populasi adalah keseluruhan subyek penelitian (Arikunto, 2006). Populasi pada penelitian ini adalah seluruh peserta didik Lembaga Kursus Progess Pare Kediri pada bulan September 2014 dengan karakteristik peserta didik yang terdapat 106 peserta didik yang menjadi target penelitian

Sampel adalah sebagian objek yang diteliti dan dianggap mewakili seluruh populasi (Notoatmodjo,2010).

Sampel yang akan diteliti adalah sampel yang tidak teridentifikasi (nonprobability sampling) dengan teknik pengambilan sampel yang digunakan dalam penelitian ini adalah Random sampling karena peserta didik Lembaga Kursus Pare Progress di Kediri memiliki karakteristik yang cenderung seragam (homogen) antara satu dengan yang lain. Untuk menentukan unit sampel penelitian dengan cara menghubungi peserta didik yang sesuai dengan kriteria penelitian satu persatu.

Penelitian dilakukan melalui kuesioner yang dibagikan kepada peserta didik saat mengikuti pembelajaran yang hadir saat peneliti hadir di lembaga pendidikan. Wawancara dilakukan untuk mengetahui sikap atau persepsi peserta didik mengenai Lembaga Kursus Pare Progress Kediri.

Pada pengambilan sampel penelitian, peneliti menggunakan rumus untuk menentukan besar sampel yang kurang dari 1000, yaitu :

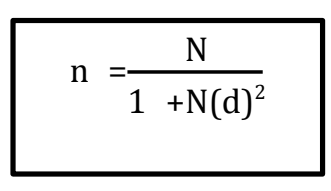

$$
\begin{aligned}
& \text { dimana : } \\
& \begin{aligned}
n & =\text { Jumlah sampel } \\
N & =\text { Jumlah populasi } \\
. . & 3,55 \\
\mathrm{n} & =28,73
\end{aligned}
\end{aligned}
$$

Jadi, jumlah responden ditentukan sebanyak 29 orang yang hadir pada jam 08.00 sampai dengan 13.00. wib tanpa dipilih (jadi secara acak).

\section{Jenis dan Sumber data Penelitian}

Jenis data dalam peneltian ini adalah data kualitatif yang dikuantitatifkan, yaitu data yang berhubungan dengan kategorisasi, karakteristik berwujud pertanyaan atau berupa kata-kata yang diangkakan. Sumber data dalam penelitian ini adalah berupa sumber data primer yaitu data yang diperoleh langsung dari responden melalui angket (kuesioner), pengamatan dan data sekunder yang diperoleh dari literatur-literatur bahan kepustakaan dan dokumen-dokumen perusahaan yang berhubungan dengan masalah yang akan diteliti. Jadi sumber data primer yang ditetapkan sebagai responden dalam penelitian ini adalah peserta didik LPK Progress Pare.

\section{Metode Pengumpulan Data}

Metode yang digunakan data berbentuk data kualitatif yang kemudian diolah menggunakan skala Likert. Skala ini digunakan untuk mengukur sikap, pendapat dan persepsi seseorang atau sekelompok tentang kejadian atau gejala 
sosial (Ridwan dan Akdom, 2007, hal.16). Dalam kuesioner yang digunakan penulis, setiap pertanyaan terdiri dari 5 (lima) kategori jawaban, yaitu $S T S=1$, TS $=2, \mathrm{~N}=3, \mathrm{~S}=4, \mathrm{SS}=5$.

Data primer berasal dari wawancara dengan beberapa peserta didik untuk memperoleh informasi tentang atribut-atribut pembentuk kualitas layanan serta kepuasan peserta didik yang dianggap penting oleh peserta didik Lembaga Kursus Progress serta data-data yang diperoleh dari hasil penyebaran kuesioner yang menunjukkan tentang tanggapan responden terhadap kualitas layanan dan kepuasan peserta didik yang diperoleh peserta didik setelah menggunakan layanan yang diberikan Lembaga Kursus dan Pelatihan Progress.

Setelah kuesioner yang telah diisi responden atau data primer tersebut terkumpul, data tersebut diperiksa dan ditabulasikan sesuai dengan kebutuhan analisis untuk memperoleh data yang dapat dipertanggung jawabkan agar apa yang menjadi penelitian dan pembahasan nanti benar-benar menunjukkan hasil yang tepat dan akurat.

Setelah kuesioner yang telah diisi responden atau data primer tersebut terkumpul, data tersebut diperiksa dan ditabulasikan sesuai dengan kebutuhan analisis untuk memperoleh data yang dapat dipertanggung jawabkan agar apa yang menjadi penelitian dan pembahasan nanti benar-benar menunjukkan hasil yang tepat dan akurat.

\section{Definisi Operasional dan Pengukuran Variabel}

Untuk memperjelas apa yang akan diteliti, maka dapat dijelaskan konsep dan definisi operasional adalah sebagai berikut:

Tabel 1

Definisi Variabel

\begin{tabular}{|c|c|c|}
\hline $\begin{array}{l}\text { Vari } \\
\text { abel }\end{array}$ & Indikator & Satuan Ukur \\
\hline $\begin{array}{l}1 . \\
\text { Harga } \\
\left(X_{1.1}\right)\end{array}$ & $\begin{array}{l}\text { a. Harga yang ditawarkan } \\
\text { terjangkau } \\
\text { b. Harga sesuai dengan fasilitas } \\
\text { yang disediakan }\end{array}$ & $\begin{array}{l}\text { Diukur dengan kepahaman } \\
\text { konsumen. Dan setiap indokator } \\
\text { diukur dengan skala likert. }\end{array}$ \\
\hline $\begin{array}{l}2 . \\
\text { Tempat } \\
\left(X_{1.2}\right)\end{array}$ & $\begin{array}{l}\text { a. Tempat proses belajar cukup } \\
\text { nyaman } \\
\text { b. Lokasi strategis dan mudah } \\
\text { dijangkau }\end{array}$ & $\begin{array}{l}\text { Diukur dengan ketertarikan } \\
\text { konsumen. Dan setiap indokator } \\
\text { diukur dengan skala likert. }\end{array}$ \\
\hline $\begin{array}{l}\quad 3 . \\
\text { Produk } \\
\left(\mathrm{X}_{1.3}\right)\end{array}$ & $\begin{array}{l}\text { a. Produk yang ditawarkan sesuai } \\
\text { dengan kebutuhan anda } \\
\text { b. Pilihan produk mampu menarik } \\
\text { minat konsumen }\end{array}$ & $\begin{array}{l}\text { Diukur dengan ketertarikan } \\
\text { konsumen. Dan setiap indokator } \\
\text { diukur dengan skala likert. }\end{array}$ \\
\hline $\begin{array}{l}\quad 4 . \\
\text { Promosi } \\
\left(\mathrm{X}_{1.4}\right)\end{array}$ & $\begin{array}{l}\text { a. Iklan selalu up to date } \\
\text { b. Iklan yang disampaikan } \\
\text { mempengaruhi daya tarik } \\
\text { konsumen }\end{array}$ & $\begin{array}{l}\text { Diukur dengan } \quad \text { ketertarikan } \\
\text { konsumen } \\
\text { likert }\end{array}$ \\
\hline $\begin{array}{l}5 . \\
\text { Orang } \\
\left(X_{1.5}\right)\end{array}$ & $\begin{array}{l}\text { a. Front Office melayani dengan } \\
\text { baik } \\
\text { b. Kemampuan tutor sesuai } \\
\quad \text { dengan harapan konsumen } \\
\end{array}$ & $\begin{array}{l}\text { Diukur dengan kepahaman } \\
\text { konsumen. Dan } \\
\text { setiap indokator diukur dengan } \\
\text { skala likert. }\end{array}$ \\
\hline Lingkungan & a. Kondisi ruang belajar terlihat & Diukur dengan kepahaman dan \\
\hline
\end{tabular}




\begin{tabular}{|c|c|c|}
\hline $\begin{array}{l}\text { Vari } \\
\text { abel }\end{array}$ & Indikator & Satuan Ukur \\
\hline Fisik $\left(\mathrm{X}_{1.6}\right)$ & $\begin{array}{l}\text { bersih dan nyaman } \\
\text { b. Sarana prasarana belajar } \\
\text { tertata rapi }\end{array}$ & $\begin{array}{l}\text { ketertarikan } \\
\text { menggunakan skala likert }\end{array}$ \\
\hline $\begin{array}{l}7 . \\
\text { Proses } \\
\left(X_{1.7}\right)\end{array}$ & $\begin{array}{l}\text { a. Hasil yang diterima tepat waktu } \\
\text { dan sesuai dengan harapan } \\
\text { b. Pengelola menjamin } \\
\text { kenyamanan dan keamanan } \\
\text { selama proses belajar }\end{array}$ & $\begin{array}{lc}\text { Diukur dengan } & \text { kepahaman dan } \\
\text { ketertarikan } & \text { konsumen } \\
\text { menggunakan skala likert }\end{array}$ \\
\hline $\begin{array}{l}\text { 8. Sikap } \\
\text { Konsumen } \\
\left(\mathrm{X}_{2}\right)\end{array}$ & $\begin{array}{l}\text { a. Konsumen mengevaluasi } \\
\text { setiap produk yang ditawarkan } \\
\text { b. Konsumen memberikan respon } \\
\text { positif setelah mendengarkan } \\
\text { penjelasan tentang berbagai } \\
\text { produk yang ditawarkan }\end{array}$ & $\begin{array}{l}\text { Diukur dengan kepahaman dan } \\
\text { ketertarikan konsumen } \\
\text { menggunakan skala likert }\end{array}$ \\
\hline $\begin{array}{l}\text { 9. Keputusan } \\
\text { Peserta Didik } \\
\text { Untuk } \\
\text { Mengikuti } \\
\text { Kursus }(\mathrm{Y})\end{array}$ & $\begin{array}{l}\text { a. Konsumen mencari informasi } \\
\text { mengenai produk yang } \\
\text { ditawarkan r pebelum } \\
\text { memutuskan program yang } \\
\text { akan diambil } \\
\text { b. Konsumen mengambil } \\
\begin{array}{l}\text { program } \\
\text { dipertimbangkan }\end{array}\end{array}$ & $\begin{array}{l}\text { Diukur dengan kepercayaan dan } \\
\text { keyakinan konsumen untuk } \\
\text { menggunakan jasa tersebut. Dan } \\
\text { setiap indokator diukur dengan } \\
\text { skala likert. }\end{array}$ \\
\hline
\end{tabular}

Sumber: Kerangka Konseptual

\section{Instrumen Penelitian}

Instrumen penelitian menggunakan kuesioner dengan pertanyaan terbuka dan skala

likert dari 1-5. Teknik analisis dengan menggunakan software SPSS 16 yang terdiri dari:

Uji Validitas, Reliabilitas, Regresi Linear Berganda, Uji F serta Uji T.

\section{Hasil Penelitian dan Pembahasan}

\section{Karakteristik Responden}

Karakteristik responden yang diteliti berdasarkan hasil penyebaran kuisioner didasarkan pada jenis kelamin, pendidikan dan umur sebagai berikut :

\section{Jenis Kelamin}

Karakteristik responden yang diteliti berdasarkan hasil penyebaran kuisioner pada jenis kelamin responden diketahui sebagai berikut :

Tabel 2

Karakteristik Responden Menurut Jenis kelamin

\begin{tabular}{|l|l|l|}
\hline Jenis Kelamin & Jumlah & Persentase \\
\hline Laki-laki & 15 & $51 \%$ \\
\hline Perempuan & 14 & $49 \%$ \\
\hline Total & 29 & $100 \%$ \\
\hline
\end{tabular}


Sumber :Data primer diolah, Tahun 2014.

Berdasarkan table di atas maka dapat diketahui jumlah responden antara laki-laki dan perempuan hampir sama.

\section{Pendidikan}

Karakteristik tingkat pendidikan yang diteliti berdasarkan hasil penyebaran kuisioner pada siswa Ipk diketahui sebagai berikut :

\section{Tabel 3}

Karakteristik Responden Menurut Pekerjaan

\begin{tabular}{|l|l|l|}
\hline Pendidikan & Jumlah & Persentase \\
\hline SD & 9 & $31 \%$ \\
\hline SMP & 10 & $34,5 \%$ \\
\hline SMA & 10 & $34,5 \%$ \\
\hline Total & 29 & $100 \%$ \\
\hline
\end{tabular}

Sumber :Data primer diolah, Tahun 2014.

Berdasarkan table 4.2, diketahui bahwa responden dari SD sebanyak 9 orang (31\%), SMP sebanyak 10 orang (34,5\%), SMA sebanyak 10 orang $(36,5 \%)$. Dengan demikian, jumlah responden SMA merupakan kelompok yang paling besar.

Umur

Karakteristik umur yang diteliti berdasarkan hasil penyebaran kuisioner pada siswa Ipk diketahui sebagai berikut :

Tabel 4

Karakteristik Responden Menurut Umur

\begin{tabular}{|l|l|l|}
\hline Umur & Jumlah & Persentase \\
\hline $8-12$ tahun & 9 & $31 \%$ \\
\hline $13-15$ tahun & 10 & $34,5 \%$ \\
\hline $15-18$ tahun & 10 & $34,5 \%$ \\
\hline Jumlah & 29 & $100 \%$ \\
\hline
\end{tabular}

Sumber: Data primer diolah, Tahun 2014.

Berdasarkan table 4.3, diketahui bahwa responden dari umur 8 -12 tahun sebanyak 9 orang (31\%), umur $13-15$ tahun sebanyak 10 orang $(34,5 \%)$, umur 15- 18 tahun sebanyak 10 orang (34,5\%). Dengan demikian, jumlah umur 15- 18 tahun merupakan kelompok yang paling besar.

\section{Uji Validitas}

Validitas adalah suatu ukuran yang digunakan dalam mengukur tingkat kevalidan atau keabsahan suatu instrumen penelitian. Suatu instrumen penelitian yang valid mempengaruhi validitas yang tinggi. Sebaliknya suatu instrumen yang kurang valid akan memiliki validitas rendah.

Suatu instrumen yang dikatakan valid, apabila mampu mengukur apa yang diinginkan, sebab suatu instrumen yang dikatakan valid apabila suatu instrumen 
penelitian dapat mengungkapkan data dari variabel yang diteliti.

Menurut Sugiyono (2009 : 106) bahwa syarat minimum yang dianggap memenuhi syarat valid adalah $r=0,30$. Berdasarkan uraian tersebut di atas maka dapat disajikan hasil olahan data mengenai pengujian validitas data dalam instrumen penelitian yang dapat dilihat melalui tabel 4.4 berikut ini :

Tabel 5

HASIL PENGUJIAN VALIDITAS ATAS PENGARUH BAURAN PEMASARAN DAN SIKAP KONSUMEN TERHADAP KEPUTUSAN MENGIKUTI JASA KURSUS

\begin{tabular}{|c|c|c|c|c|}
\hline Variabel & $\begin{array}{l}\text { Kode Item } \\
\text { Pertanyaan }\end{array}$ & rhit & rtabel & Keterangan \\
\hline 1. Harga & $\begin{array}{l}\mathrm{H} 1 \\
\mathrm{H} 2\end{array}$ & $\begin{array}{l}0,630 \\
0,716\end{array}$ & 0,367 & Valid \\
\hline 2. Tempat & $\begin{array}{l}\text { T3 } \\
\text { T4 }\end{array}$ & $\begin{array}{l}0,650 \\
0,841\end{array}$ & 0,367 & Valid \\
\hline 3. Produk & $\begin{array}{l}\text { P5 } \\
\text { P6 }\end{array}$ & $\begin{array}{l}0,804 \\
0,764\end{array}$ & 0,367 & Valid \\
\hline 4. Promosi & $\begin{array}{l}\text { P7 } \\
\text { P8 }\end{array}$ & $\begin{array}{l}0,859 \\
0,806\end{array}$ & 0,367 & Valid \\
\hline 5. Orang & $\begin{array}{l}09 \\
010\end{array}$ & $\begin{array}{l}0,796 \\
0,618 \\
\end{array}$ & 0,367 & Valid \\
\hline $\begin{array}{ll}\text { 6. } & \text { Lingkunga } \\
\text { n Fisik }\end{array}$ & $\begin{array}{l}\mathrm{L} 11 \\
\mathrm{~L} 12\end{array}$ & $\begin{array}{l}0,710 \\
0,856\end{array}$ & 0,367 & Valid \\
\hline 7. Proses & $\begin{array}{l}\text { P13 } \\
\text { P14 }\end{array}$ & $\begin{array}{l}0,916 \\
0,876\end{array}$ & 0,367 & Valid \\
\hline 8. Sikap & $\begin{array}{l}\text { S15 } \\
\text { S16 }\end{array}$ & $\begin{array}{l}0,723 \\
0,769\end{array}$ & 0,367 & Valid \\
\hline 9. Keputusan & $\begin{array}{l}\text { K17 } \\
\text { K18 }\end{array}$ & $\begin{array}{l}0,773 \\
0,597\end{array}$ & 0,367 & Valid \\
\hline
\end{tabular}

Sumber: Data primer diolah, Tahun 2014 (Lampiran 2 Halaman 87)

Berdasarkan tabel 4.4 yakni hasil olahan data mengenai pengujian validitas, menunjukkan bahwa untuk setiap masing-masing variabel memiliki 2 item pertanyaan sehingga total seluruh pertanyaan sebanyak 18 item. Maka dapat disimpulkan bahwa 18 item pertanyaan sudah valid karena memiliki nilai korelasi di atas dari 0,367.

\section{Uji Reliabilitas}

Reliabilitas menunjukkan sesuatu instrumen yang dapat digunakan sebagai alat pengumpul data, karena instrumen dapat dipercaya dan reliabel yang akan menghasilkan data yang dapat dipercaya. Suatu data instrumen penelitian dikatakan reliabel menurut Ghozali (2006 : 133) apabila memiliki nilai cronbach's alpha $>0,60$.

Adapun hasil olahan data mengenai reliabilitas data instrumen penelitian yaitu sebagai berikut :

Tabel 6

HASIL ANALISIS RELIABILITAS DATA INSTRUMEN PENELITIAN PENGARUH BAURAN PEMASARAN DAN SIKAP KONSUMEN TERHADAP KEPUTUSAN MENGIKUTI JASA KURSUS 


\begin{tabular}{|l|l|l|l|l|}
\hline Variabel & \multicolumn{1}{|c|}{$\begin{array}{c}\text { Kode Item } \\
\text { Pertanyaan }\end{array}$} & $\begin{array}{c}\text { Cronbach } \\
\text { s Alpha }\end{array}$ & $\begin{array}{c}\text { Cronbach's } \\
\text { Alpha } \\
\text { Standar }\end{array}$ & Keterangan \\
\hline 1. Harga & $\mathrm{H}$ & 0,713 & 0,60 & Reliabel \\
2. Tempat & $\mathrm{T}$ & 0,793 & 0,60 & Reliabel \\
3. Produk & & 0,820 & 0,60 & Reliabel \\
4. Promosi & $\mathrm{P}$ & 0,854 & 0,60 & Reliabel \\
5. Orang & $\mathrm{P}$ & 0,756 & 0,60 & Reliabel \\
6. Lingkungan & $\mathrm{O}$ & 0,821 & 0,60 & Reliabel \\
$\quad$ Fisik & $\mathrm{L}$ & 0,890 & 0,60 & Reliabel \\
7.Proses & $\mathrm{P}$ & 0,788 & 0,60 & Reliabel \\
8. Sikap \\
$\begin{array}{l}\text { Konsumen } \\
\text { 9. Keputusan }\end{array}$ & $\mathrm{S}$ & 0,732 & 0,60 & Reliabel \\
& $\mathrm{K}$ & & & \\
\hline
\end{tabular}

Sumber: Data primer diolah, Tahun 2014 (Lampiran 2, Halaman 87)

Berdasarkan tabel 4.5 yakni hasil pengolahan data mengenai reliabilitas, yang menunjukkan bahwa semua item pernyataan yang diajukan sudah reliabel atau handal, hal ini dapat dilihat dari variabel Harga memiliki nilai cronbach's alpha 0,713, untuk Tempat memiliki cronbach's alpha sebesar 0,793, untuk variabel Produk memiliki nilai cronbach's alpha 0,820, untuk Promosi memiliki nilai cronbach's alpha sebesar 0,854, untuk Orang memiliki nilai cronbach's alpha 0,756, untuk Lingkungan Fisik memiliki nilai cronbach's alpha 0,821, untuk Proses memiliki nilai cronbach's alpha 0,890, untuk Sikap Konsumen memiliki nilai cronbach's alpha 0,890 dan untuk variabel keputusan memiliki nilai cronbach's alpha 0,732, sehingga dapat disimpulkan bahwa semua variabel sudah handal karena memiliki nilai cronbach's alpha diatas dari 0,60.

\section{Uji Asumsi Klasik}

Uji asumsi klasik bertujuan untuk memastikan bahwa metode multivariate, termasuk metode regresi dapat digunakan pada data tertentu sehingga dapat diinterpretasikan dengan tepat (Santoso, 2003). Uji ini mengukur asumsi Heteroskedastisitas, Multikokolinieritas, dan Normalitas. Model regresi yang digunakan benar-benar menunjukkan hubungan yang signifikan dan representative jika model tersebut memenuhi asumsi dasar klasik regresi.

\section{Analisis Regresi Linear Berganda}

Analisis regresi antara pengaruh harga,tempat, produk, promosi, orang, lingkungan fisik, proses dan sikap konsumen terhadap keputusan mengikuti kursus dimaksudkan untuk mengetahui pola dan mengukur perubahan pengaruh faktor Bauran Pemasaran terhadap keputusan mengikuti kursus di lpk progress.

Berdasarkan pengolahan data hasil kuesioner dengan menggunakan komputerisasi dengan program SPSS diperoleh hasil seperti pada tabel 4.6 berikut ini : 
FISIK, PROSES DAN SIKAP KONSUMEN TERHADAP KEPUTUSAN MENGIKUTI KURSUS

\begin{tabular}{|l|l|l|l|}
\hline Variabel & Koefisien regresi & Sig & $\mathbf{t}_{\text {hit }}$ \\
\hline (Constant) & 9.789 & .014 & 2.683 \\
\hline Harga & -1.010 & .003 & -3.381 \\
\hline Tempat & .205 & .285 & 1.098 \\
\hline Produk & .344 & .182 & 1.384 \\
\hline Promosi & -.143 & .432 & -.801 \\
\hline Orang & .158 & .555 & .600 \\
\hline $\begin{array}{l}\text { Lingkungan_Fisi } \\
\mathrm{k}\end{array}$ & -.289 & .082 & -1.831 \\
\hline Proses & .411 & .017 & 2.590 \\
\hline $\begin{array}{l}\text { Sikap_Konsume } \\
\mathrm{n}\end{array}$ & .257 & .154 & 1.438 \\
\hline $\begin{array}{l}\mathrm{R}=0,706 \\
\mathrm{R}^{2}=0,499\end{array}$ & \multicolumn{3}{|l|}{$\begin{array}{l}\text { Sig }=0,047 \\
\text { Sumber :Data primer diolah, Tahun 2014 (Lampiran 2, Halaman 96) }\end{array}$} \\
\hline
\end{tabular}

Berdasarkan tabel 4.6 yang diperoleh dari hasil pengolahan data komputerisasi dengan menggunakan program SPSS maka diperoleh persamaan regresi berganda sebagai berikut :

$Y=9,789+-1,010 X_{1.1}+0,205 X_{1.2}+0,344 X_{1.3}+-0,143 X_{1.4}+0,158 X_{1.5}+-0,289$ $\mathrm{X}_{1.6}+0,411 \mathrm{X}_{1.7}+0,257 \mathrm{X}_{.2}$

Persamaan regresi di atas dapat dijelaskan sebagai berikut :

$\mathrm{b}_{0}=9,789$ menunjukkan bahwa Harga, Tempat, Produk, Promosi, Orang, Lingkungan Fisik, Proses dan Sikap Konsumen mempengaruhi keputusan sebesar $9,789 \%$

$b_{1}=-1,010$ menunjukkan bahwa jika harga ditingkatkan satu satuan maka tidak berpengaruh terhadap keputusan

$b_{2}=0,205$ menunjukkan bahwa jika Tempat ditingkatkan sebesar satu satuan maka dapat diikuti oleh keputusan sebesar 0, $205 \%$.

$b_{3}=0,344$ menunjukkan bahwa Produk ditingkatkan sebesar satu satuan maka dapat diikuti oleh peningkatan keputusan sebesar 0,344 \%.

$\mathrm{b}_{4}=-0,143$ menunjukkan bahwa jika Promosi ditingkatkan sebesar satu satuan maka tidak berpengaruh terhadap keputusan

$b_{5}=0,158$ menunjukkan bahwa Orang/SDM ditingkatkan sebesar satu satuan maka dapat diikuti oleh peningkatan keputusan sebesar 0,158 \%.

$b_{6}=-0,289$ menunjukkan bahwa Lingkungan Fisik ditingkatkan sebesar satu satuan maka tidak berpengaruh terhadap keputusan

$b_{7}=0,411$ menunjukkan bahwa Proses ditingkatkan sebesar satu satuan maka dapat diikuti oleh peningkatan keputusan sebesar 0,411\%.

$\mathrm{b}_{8}=0,257$ menunjukkan bahwa Sikap Konsumen ditingkatkan sebesar satu satuan maka dapat diikuti oleh peningkatan keputusan sebesar $0,257 \%$. 
Analisis Data

Tabel 8

Koefisien Determinasi

Model Summary

\begin{tabular}{|l|l|l|l|l|}
\hline Model & \multicolumn{1}{|c|}{$\mathrm{R}$} & $\mathrm{R}$ Square & $\begin{array}{c}\text { Adjusted R } \\
\text { Square }\end{array}$ & $\begin{array}{c}\text { Std. Error of } \\
\text { the Estimate }\end{array}$ \\
\hline 1 & $.706^{\mathrm{a}}$ & .499 & .298 & .820 \\
\hline
\end{tabular}

a. Predictors: (Constant), Sikap_Konsumen, Harga, Lingkungan_Fisik, Produk, Tempat, Proses, Orang,

Promosi

Sumber: Data primer diolah, Tahun 2014 (Lampiran 2, Halaman 96)

Dalam regresi linear berganda, nilai $\mathrm{R}$ sebesar 0,706 menunjukkan korelasi ganda (bauran pemasaran dan sikap konsumen) dengan keputusan mengikuti kursus. Nilai Adjusted R Square sebesar 0,298menunjukkan besarnya peran atau kontribusi variabel bauran pemasaran dan sikap konsumen terhadap variabel keputusan mengikuti jasa sebesar $29 \%$.

Uji hipotesis

Uji Hipotesis 1

Dalam penelitian ini terdapat dua hipotesis yang akan di uji, untuk menguji hipotesis dapat dilakukan uji f dan uji t. Adapun uji hipotesis tersebut adalah sebagai berikut:

1. Uji F

Pada penelitian ini, uji $\mathrm{F}$ digunakan untuk mengetahui signifikansi pengaruh harga,tempat, produk, promosi, orang, lingkungan fisik, proses dan sikap konsumen terhadap keputusan mengikuti kursus. Uji $F$ dilakukan dengan membandingkan $\mathrm{F}$ hitung dengan $\mathrm{F}$ tabel.

Jika $f_{\text {hitung }}$ lebih kecil daripada $f_{\text {tabel }}$ maka $h_{0}$ ditolak dan $h_{1}$ diterima, begitu pula sebaliknya. Sedangkan hipotesis $f$ adalah sebagai berikut :

$\mathrm{H}_{0}=$ tidak ada pengaruh antara variabel bauran pemasaran (harga,tempat, produk, promosi, orang, lingkungan fisik, proses) dan sikap konsumen secara bersama-sama terhadap keputusan mengikuti kursus

$\mathrm{H}_{1}=$ ada pengaruh antara variabel bauran pemasaran (harga,tempat, produk, promosi, orang, lingkungan fisik, proses) dan sikap konsumen secara bersama-sama terhadap keputusan mengikuti kursus

Tabel 9

Hasil Regresi Uji F

ANOVA $^{\mathrm{b}}$

\begin{tabular}{|l|l|l|l|l|l|}
\hline \multicolumn{1}{|c|}{ Model } & \multicolumn{1}{c|}{ Sum of Squares } & Df & Mean Square & F & Sig. \\
\hline Regression & 13.374 & 8 & 1.672 & 2.485 & $.047^{\mathrm{a}}$ \\
Residual & 13.453 & 20 & .673 & & \\
Total & 26.828 & 28 & & & \\
\hline
\end{tabular}

a. Predictors: (Constant), Sikapkonsumen_X2, Orang_X1.5, Lingkunganfisik_X1.6, Harga_X1.1, Promosi_X1.4, Proses_X1.7, Tempat_X1.2, Produk_X1.3

Berdasarkan hasil regresi dari tabel diatas menunjukkan bahwa $F$ hitung 
sebesar 2,485 atau 2,49 (pembulatan 2 angka dibelakang koma) dengan nilai signifikansi 0,047 . Untuk mengetahui $F$ tabel, terlebih dahulu dutentukan derajat kebebasan (df1 dan df2). Dengan menggunakan signifikansi $a=5 \%$, df1 (jumlah variabel -1$)=8$, dan df2 $(n-k-1)$ atau 29-8-1 $=20$ (dimana $n$ adalah jumlah responden dan $\mathrm{k}$ adalah jumlah variabel independen). Untuk tabel $\mathrm{F}$ yang disusun oleh Junaidi Chaniago ( 2008, diakses 4 Mei 2012), df1 disebut sebagai df untuk pembilang (N1) dan df2 disebut sebagi df untuk penyebut (N2). Dengan demikian, $F$ tabel yang dicari terdapat diantara baris $N 2=20$ dengan kolom $N 1=8$. Sehingga $F$ tabel yang diperoleh adalah 2,45 . Dengan demikian $F$ hitung $>F$ tabel $(2,49>$ 2,45), maka bauran pemasaran dan sikap konsumen mempunyai pengaruh signifikan secara simultan terhadap keputusan mengikuti kursus di Ipk progress pare $\left(\mathrm{H}_{0}\right.$ ditolak $)$ dan $\left(\mathrm{H}_{1}\right.$ diterima $)$.

2. $\quad$ Uji T

Pengujian ini dilakukan untuk mengetahui apakah variabel $X$ berpengaruh positif secara parsial terhadap variabel Y. Uji t dilakukan dengan membandingkan nilai t hitung dengan $t$ tabel. Dari pebandingan $t$ hitung dan $t$ tabel, Dimana $\mathrm{T}_{\text {tabel }}>\mathrm{T}_{\text {hitung, }} \mathrm{H}_{0}$ diterima. Dan jika $\mathrm{T}_{\text {tabel }}<\mathrm{T}_{\text {hitung, }}$ maka $\mathrm{H}_{1}$ diterima, begitupun jika sig $>\alpha(0.05)$, maka $\mathrm{H}_{0}$ diterima $\mathrm{H}_{1}$ ditolak dan jika sig $<\alpha(0,05)$, maka maka $\mathrm{H}_{0}$ ditolak $\mathrm{H}_{1}$ diterima.

$$
\begin{aligned}
& \mathrm{H}_{0}=\text { tidak ada pengaruh positif } \\
& \mathrm{H}_{1}=\text { ada pengaruh positif }
\end{aligned}
$$

Tabel 10

RINGKASAN PENGUJIAN VARIABEL INDEPENDEN TERHADAP VARIABEL DEPENDEN SECARA PARSIAL

\begin{tabular}{|c|c|c|c|c|c|c|}
\hline & \multirow{2}{*}{ Model } & \multicolumn{2}{|c|}{$\begin{array}{l}\text { Unstandardized } \\
\text { Coefficients }\end{array}$} & \multirow{2}{*}{$\begin{array}{c}\begin{array}{c}\text { Standardized } \\
\text { Coefficients }\end{array} \\
\text { Beta }\end{array}$} & \multirow{2}{*}{$\mathrm{T}$} & \multirow{2}{*}{ Sig } \\
\hline & & B & $\begin{array}{l}\text { Std. } \\
\text { Error }\end{array}$ & & & \\
\hline \multirow[t]{9}{*}{1} & (Constant) & 9.789 & 3.648 & & 2.683 & .014 \\
\hline & Harga_X1.1 & -1.010 & .299 & -.670 & -3.381 & .003 \\
\hline & Tempat_X1.2 & .205 & .187 & .220 & 1.098 & .285 \\
\hline & Produk_X1.3 & .344 & .249 & .377 & 1.384 & .182 \\
\hline & Promosi_X1.4 & -.143 & .179 & -.192 & -.801 & .432 \\
\hline & Orang_X1.5 & .158 & .263 & .129 & .600 & .555 \\
\hline & Lingkunganfisik_X1.6 & -.289 & .158 & -.352 & -1.831 & .082 \\
\hline & Proses_X1.7 & .411 & .159 & .518 & 2.590 & .017 \\
\hline & Sikapkonsumen_X2 & .257 & .173 & .257 & 1.483 & .154 \\
\hline
\end{tabular}

Coefficients $^{a}$

a. Dependent

Variable:Keputusan_Y

Sumber: Data primer diolah, Tahun 2014 (Lampiran 2, Halaman 97)

Sesuai tabel 4.12 dapat dijelaskan pengujian secara statistik dengan uji 
parsial ( Uji T) dari masing-masing variabel yaitu :

1. Pengujian Parsial variabel Harga $\left(X_{1.1}\right)$

Nilai thitung dalam regresi menunjukkan besarnya hubungan Harga dengan Keputusan sebesar -3,381. Nilai $t$ juga menunjukkan pengaruh variabel independent secara parsial terhadap variabel dependent. Nilai probabilitas thitung sebesar 0,003 $<0,05$ meskipun signifikan namun tidak berpengaruh terhadap keputusan karena nilainya negatif sehingga $\mathrm{H}_{1}$ ditolak.

2. Pengujian Parsial Variabel Tempat $\left(X_{1.2}\right)$

Nilai thitung dalam regresi menunjukkan besarnya hubungan Tempat dengan Keputusan sebesar 1,098. Nilai $t$ juga menunjukkan pengaruh variabel independent secara parsial terhadap variabel dependent. Nilai probabilitas thitung sebesar 0,285 >0,05 menunjukkan tidak ada pengaruh signifikan antara Tempat terhadap keputusan, $\mathrm{H}_{1}$ ditolak.

3. Pengujian Parsial Variabel Produk $\left(\mathrm{X}_{1.3}\right)$

Nilai thitung dalam regresi menunjukkan besarnya hubungan Produk dengan Keputusan sebesar 1,384. Nilai $t$ juga menunjukkan pengaruh variabel independent secara parsial terhadap variabel dependent. Nilai probabilitas $t_{\text {hitung }}$ sebesar 0,182 >0,05 menunjukkan tidak ada pengaruh signifikan antara Produk terhadap keputusan, $\mathrm{H}_{1}$ ditolak.

4. Pengujian Parsial Variabel Promosi ( $\left.\mathrm{X}_{1.4}\right)$

Nilai thitung dalam regresi menunjukkan besarnya hubungan Promosi dengan Keputusan sebesar $-0,801$. Nilai $t$ juga menunjukkan pengaruh variabel independent secara parsial terhadap variabel dependent. Nilai probabilitas thitung sebesar 0,432 >0,05 menunjukkan tidak ada pengaruh signifikan antara Promosi terhadap keputusan, $\mathrm{H}_{1}$ ditolak.

5. Pengujian Parsial Variabel Orang $\left(\mathrm{X}_{1.5}\right)$

Nilai thitung dalam regresi menunjukkan besarnya hubungan Orang dengan Keputusan sebesar 0,600. Nilai $t$ juga menunjukkan pengaruh variabel independent secara parsial terhadap variabel dependent. Nilai probabilitas thitung sebesar 0,555 > 0,05 menunjukkan tidak ada pengaruh signifikan antara Orang terhadap keputusan, $\mathrm{H}_{1}$ ditolak.

6. Pengujian Parsial Variabel Lingkungan Fisik $\left(X_{1.6}\right)$

Nilai thitung dalam regresi menunjukkan besarnya hubungan Lingkungan Fisik dengan Keputusan sebesar -1831. Nilai t juga menunjukkan pengaruh variabel independent secara parsial terhadap variabel dependent. Nilai probabilitas

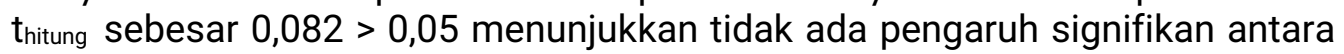
Lingkungan Fisik terhadap keputusan, $\mathrm{H}_{1}$ ditolak

7. Pengujian Parsial Variabel Proses $\left(\mathrm{X}_{1.7}\right)$

Nilai thitung dalam regresi menunjukkan besarnya hubungan Proses dengan Keputusan sebesar 2,590. Nilai $t$ juga menunjukkan pengaruh variabel independent secara parsial terhadap variabel dependent. Nilai probabilitas thitung sebesar 0,014 < 0,05 menunjukkan ada pengaruh signifikan antara Proses terhadap keputusan, $\mathrm{H}_{1}$ diterima.

8. Pengujian Parsial Variabel Sikap Konsumen ( $\left.\mathrm{X}_{2}\right)$

Nilai thitung dalam regresi menunjukkan besarnya hubungan Sikap Konsumen dengan Keputusan sebesar 1,438. Nilai t juga menunjukkan pengaruh variabel independent secara parsial terhadap variabel dependent. Nilai probabilitas thitung sebesar 0,154 > 0,05 menunjukkan tidak ada pengaruh signifikan antara Sikap Konsumen terhadap keputusan konsumen, $\mathrm{H}_{1}$ ditolak.

Dari hasil diatas dapat dikatakan bahwa variabel proses secara parsial 
berpengaruh signifikan terhadap keputusan.

\section{Uji Hipotesis 2}

Berdasarkan tabel 4.14 dapat diketahui dari koefisien regresi yang terstandartkan (Standarized Coefficients) bahwa variabel prosesmempunyai koefisien terbesar yaitu sebesar 0,518 dibandingkan variabel lainnya sehingga dapat dikatakan bahwa variabel proses mempunyai pengaruh terbesar/dominan terhadap keputusan, sehingga hipotesis yang kedua terbukti atau diterima.

\section{Pembahasan}

Dari hasil uji $\mathrm{F}$ yang disajikan pada table 4.13 diperoleh hasil signifikansi sebesar 0,047 dimana hasil uji $F$ tersebut lebih kecil dari 0,05 $(a=5 \%)$. Ini berarti variabel bauran pemasaran dan sikap konsumen secara simultan berpengaruh signifikan terhadap keputusan mengikuti jasa kursus di LPK Progres Pare.

Berdasarkan uji $\mathrm{T}$ yang disajikan dalam table 4.14 diperoleh hasil signifikansi variabel harga sebesar 0,003 dimana hasil uji T tersebut kurang dari 0,05 . Hal ini menunjukkan bahwa variabel harga di LPK Progress Pare signifikan namun tidak berpengaruh terhadap keputusan karena mempunyai nilai $T$ hitung yang negatif. Begitu juga dengan variabel tempat, produk, promosi, orang, lingkungan fisik dan sikap konsumen sama-sama mempunyai hasil uji T lebih dari 0,05 yang menunjukkan bahwa variabel tersebut tidak berpengaruh signifikan terhadap keputusan mengikuti jasa kursus di LPK Progress.

Dari hasil uji $T$ tersebut dapat diketahui bahwa masih diperlukan peningkatan kapasitas variabel bauran pemasaran dan sikap konsumen di LPK Progess Pare melalui pengarahan dan evaluasi agar dapat menciptakan suatu ide dan pemikiran baru yang nantinya dapat meningkatkan kinerja dalam memasarkan jasanya.

Dari hasil regresi linear berganda tersebut dapat dikatakan bahwa variabel harga di Ipk progress pare mempunyai pengaruh negatif namun signifikan, artinya harga tidak berpengaruh terhadap keputusan meski harga dinaikkan atau juga diturunkan. Begitu juga dengan variabel tempat, produk, promosi, orang, lingkungan fisik dan sikap konsumen tidak memiliki pengaruh positif dan signifikan karena penerapannya dalam kegiatan pemasaran kurang maksimal sehingga perlu adanya suatu inovasi guna memperoleh hasil yang maksimal sehingga dapat berpengaruh terhadap keputusan untuk memilih kursus di LPK Progress Pare.

Sedangkan variabel proses berdasarkan uji T yang disajikan dalam tabel 4.14 diperoleh hasil signifikansi sebesar 0,017 dimana nilai signifikansi tersebut kurang dari 0,05 ( $a=5 \%$ ). Hal ini menunjukkan bahwa variabel proses di LPK Progress Pare berpengaruh signifikan terhadap keputusan para peserta kursus. Berdasarkan hasil analisis regresi linear berganda tersebut diatas dapat dikatakan bahwa variabel proses di LPK Progress Pare memiliki pengaruh signifikan yang positif terhadap keputusan peserta kursus, artinya bila variabel proses ditingkatkan maka akan menunjang peningkatan keputusan mengikuti jasa kursus di LPK Progres Pare.

Tabel 11

\section{Model Summary}




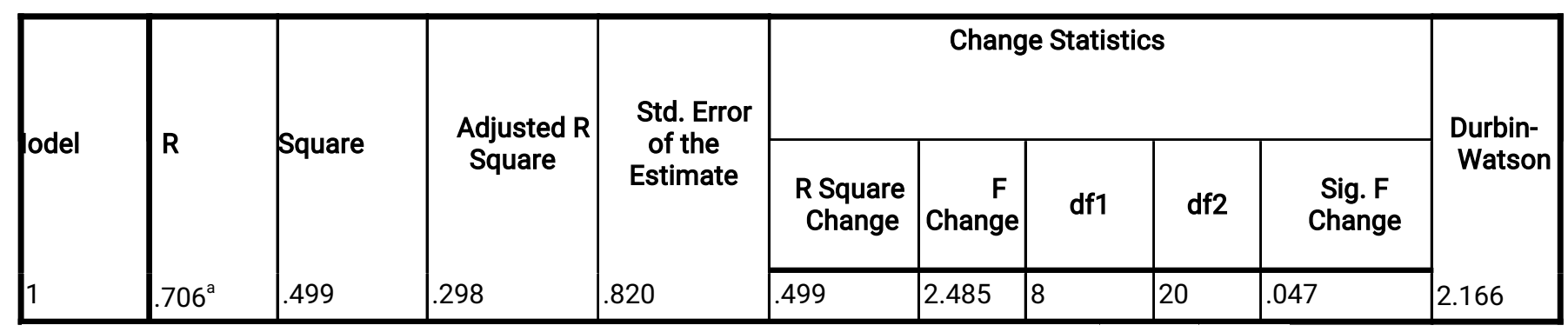

a. Predictors: (Constant), Sikap_Konsumen, Orang, Lingkungan_Fisik, Harga, Promosi, Proses, Tempat, Produk

b. Dependent Variable: Keputusan

Sumber: Data Primer Diolah, Tahun 2014 (Lampiran 2, Halaman 98)

Adapun tabel 4.15 menunjukkan angka $\mathrm{R}$ sebesar 0,706 artinya kedua variabel yaitu bauran pemasaran (X1) dan sikap konsumen (X2) berpengaruh sebesar 70,6\% terhadap keputusan mengikuti jasa kursus ( $\mathrm{Y}$ ). Adapun sisanya sebesar $29,4 \%$ disebabkan oleh variabel-variabel lain yang tidak diteliti dalam penelitian ini.

Berdasarkan hasil analisis regresi tersebut maka hipotesis penelitian, baik hipotesis 1 maupun 2 yakni : bahwa variabel bauran pemasaran dan sikap konsumen berpengaruh signifikan secara simultan terhadap keputusan peserta kursus, namun secara parsial hanya variabel proses yang berpengaruh signifikan terhadap keputusan. Sedangkan variabel proses memiliki pengaruh dominan terhadap keputusan karena dalam kegiatan belajar mengajar lembaga tersebut menjaga agar waktu kursus dapat dicapai tepat waktu sehingga tidak ada waktu yang terbuang dan peserta menyukai hal tersebut.

\section{Kesimpulan dan Saran \\ Kesimpulan}

Dari hasil yang telah disebutkan pada bab-bab sebelumnya tentang pengaruh bauran pemasaran dan sikap konsumen terhadap keputusan mengikuti jasa kursus di lpk Progress pare, dap[at ditarik kesimpulan sebagai berikut :

1. Variabel Harga $\left(X_{1.1}\right)$ secara parsial memberikan pengaruh dominan terhadap keputusan dengan nilai probabilitas 0,021 lebih kecil daripada tingkat signifikan 0,05 .

2. Variabel Lingkungan Fisik $\left(\mathrm{X}_{1.6}\right)$ secara parsial memberikan pengaruh dominan terhadap keputusan dengan nilai probabilitas 0,038 lebih kecil daripada tingkat signifikan 0,05 .

3. Variabel Proses $\left(\mathrm{X}_{1.7}\right)$ secara parsial memberikan pengaruh paling dominan terhadap keputusan dengan niali probabilitas 0,012 lebih kecil dari tingkat signifikan 0,05.

4. Variabel Bauran Pemasaran $\left(X_{1}\right)$ dan Sikap Konsumen $\left(X_{2}\right)$ secara simultan memberikan pengaruh secara signifikan terhadap Keputusan dengan nilai $F_{\text {hitung }} 2,165$ lebih kecil dari $F_{\text {tabel }} 2,45$ dan nilai probabilitasnya 0,077 .

\section{Saran}

1. Untuk meningkatkan keputusan konsumen sebaiknya dalam kegiatan memasarkan jasanya agar menciptakan suatu cara atau ide baru yang lebih menarik dari sebelumnya yaitu dengan memaksimalkan variabel bauran 
pemasaran dan sikap konsumen secara bersama-sama yang nantinya didapatkan hasil yang memuaskan dan sesuai dengan harapan.

2. Untuk lebih menguatkan semua hipotesis yang trerbukti secara empiris diterima, maka perlu adanya penelitian ulang dalam lembaga lain yang berbeda waktu dan lokasinya agar dapat diperoleh suatu kajian di masa yang akan datang.

\section{Daftar Pustaka}

Andriansyah. 2012. Analisis Pengaruh Bauran Pemasaran Dan Sikap Konsumen Terhadap Keputusan Pembelian Sepeda Motor Merek Honda Pada Dealer CV. Bina putra sanjaya lhoksukun aceh utara. Tesis, SEKOLAH PASCA SARJANA UNIVERSITAS SUMATERA UTARA MEDAN.

Freyadefunk.wordpress.com/2013/03/24/cara-menguji-normalitas-data-denganspss/ Hastono, SP. 2001. Analisis Data. Jakarta : FKM - UI.

Http://nulz-e.blogspot.com/2012/04/manajemen-pemasaran-jasa-dan-

bauran.html

Http://repository.usu.ac.id/bitstream/123456789/34176/4/Chapter\%20II.pdf

Http://susantaku.blogspot.com/p/blog-page_13.html

Kotler, K.L.Keller. 2009. Manajemen Pemasaran. Jakarta : Erlangga.

Lupioyadi, Rambat. 2013. Manajemen Pemasaran Jasa: Berbasis Kompetensi. Edisi Tiga. Jakarta: Salemba Empat.

Santosa, S. 2001. Buku Latihan Statistik Non Parametrik. Jakarta : Gramedia.

Santoso, S. 1999. SPSS Mengolah Data Statistik Secara Profesional. Jakarta : Gramedia.

Sugiyono. 2013. Metode Penelitian Pendidikan. Bandung: Alfabeta.

Wijaya, Toni. 2012. Praktis dan simple cepat menguasai SPSS 20 untuk olah dan interprentasi data. Yogyakarta : Cahaya Atma Pustaka. 
